\title{
AER1, a Major Gene Conferring Resistance to Aphanomyces euteiches in Medicago truncatula
}

\author{
M.-L. Pilet-Nayel, J.-M. Prospéri, C. Hamon, A. Lesné, R. Lecointe, I. Le Goff, M. Hervé, G. Deniot, \\ M. Delalande, T. Huguet, C. Jacquet, and A. Baranger
}

First, third, fourth, fifth, sixth, seventh, eighth, and twelfth authors: INRA, Agrocampus Ouest, Université Rennes I, UMR118, Amélioration des Plantes et Biotechnologies Végétales, Plant Genetics and Biotechnology, OUEST-genopole, Domaine de la Motte, BP35327, 35653 Le Rheu, France; second and ninth authors: INRA, UMR1097, Diversité et Adaptation des Plantes Cultivées, Domaine de Melgueil, F34130 Mauguio, France; tenth author: INP-ENSAT Laboratoire Biotechnologie et Amélioration des Plantes, Pôle de Biotechnologie Végétale, Avenue de l'Agrobiopole, BP 32607 Auzeville, 31326 Castanet-Tolosan cedex, France; and eleventh author: CNRS-Université Paul

Sabatier, UMR5546 Pôle de Biotechnologie Végétale, BP42617, 31326 Castanet-Tolosan Cedex, France.

Accepted for publication 29 September 2008

\begin{abstract}
Pilet-Nayel, M.-L., Prospéri, J.-M., Hamon, C., Lesné, A., Lecointe, R., Le Goff, I., Hervé, M., Deniot, G., Delalande, M., Huguet, T., Jacquet, C., and Baranger, A. 2009. AER1, a major gene conferring resistance to Aphanomyces euteiches in Medicago truncatula. Phytopathology 99:203208.

Aphanomyces euteiches is a major soilborne oomycete pathogen that infects various legume species, including pea and alfalfa. The model legume Medicago truncatula has recently emerged as a valuable genetic system for understanding the genetic basis of resistance to A. euteiches in leguminous crops. The objective of this study was to identify genetic determinants of resistance to a broad host-range pea-infecting strain of $A$.

euteiches in M. truncatula. Two M. truncatula segregating populations of $178 \mathrm{~F}_{5}$ recombinant inbred lines and $200 \mathrm{~F}_{3}$ families from the cross F83005.5 (susceptible) $\times$ DZA045.5 (resistant) were screened for resistance to A. euteiches. Phenotypic distributions observed suggested a dominant monogenic control of resistance. A major locus associated with resistance to A. euteiches, namely AER1, was mapped by bulk segregant analysis to a terminal end of chromosome 3 in $M$. truncatula and explained $88 \%$ of the phenotypic variation. AERI was identified in a resistance-gene-rich region, where resistance gene analogs and genes associated with disease resistance phenotypes have been identified. Discovery of $A E R I$ opens up new prospects for improving resistance to $A$. euteiches in cultivated legumes using a comparative genomics approach.
\end{abstract}

Aphanomyces euteiches Drechsler is a major soilborne oomycete pathogen that infects various legume species, including pea (Pisum sativum) (17) and alfalfa (Medicago sativa) (21). Aphanomyces root rot was first described on pea in the 1920s in Wisconsin and, since then, has been very damaging in many pea-growing areas in North America, Australia, New Zealand, Japan, and Europe (17). On alfalfa, the disease was first described in the 1920 s in the United States and is a widespread disease of alfalfa in North America (29).

Apart from avoiding highly infested fields, few methods are available to control the disease on pea. The efficacies of seed treatment, use of green manure, and biological control methods have yet to be confirmed in field studies. The development of resistant cultivars has become a major objective for most legumes crops because no highly resistant cultivars are available yet. In alfalfa, breeding for resistance to race 1 of A. euteiches (21) has led to improved stand establishment and cultivar performance in infested fields (39). In other legumes, resistance levels in genetic resources are low but some partially resistant germplasm of agronomic types has been identified or developed, especially in pea (16).

Genetics of resistance to A. euteiches is still not well characterized in most of the leguminous crops infected by the pathogen, partially due to complexity of inheritance of resistance or complexity of the genome (tetraploid alfalfa genome and large pea genome). In pea, resistance to A. euteiches has been demon-

Corresponding author: M.-L. Pilet-Nayel;

E-mail address: Marie-Laure.Pilet@rennes.inra.fr

doi:10.1094/PHYTO-99-2-0203

(C) 2009 The American Phytopathological Society strated as partial and controlled by several quantitative trait loci (QTL) (30,31). In alfalfa, nothing is known about the genes underlying resistance to A. euteiches. Vandemark et al. (36) reported on high heritabilities of resistance to races $1\left(h^{2}=0.84\right.$ to $0.90)$ and $2\left(h^{2}=0.62\right.$ to 0.66$)$ in three different half-sib family alfalfa populations evaluated in greenhouse conditions, suggesting that improvement of resistance to both races is possible through selection.

The model legume, Medicago truncatula (45), has been investigated as a genetic system for studying resistance to major diseases affecting leguminous crops (34), especially Aphanomyces root rot. Many A. euteiches strains can infect different leguminous hosts (42), including $M$. truncatula, inducing differential reactions within various legume species (24). Variation for resistance or susceptibility to A. euteiches has been reported in $M$. truncatula using A. euteiches strains isolated from alfalfa (37) or pea (25). High levels of resistance, much higher than in pea, were observed in some $M$. truncatula accessions when inoculated with RB84, a pea-infecting strain of $A$. euteiches (25).

Close phylogenetic relationships, high levels of sequence homology, and macrosynteny have been demonstrated between the genomes of $M$. truncatula and leguminous crops infected by $A$. euteiches, particularly alfalfa and pea (5). Cross-species markers based on expressed sequence tag simple sequence repeats (ESTSSRs) (9) or on candidate genes of known function $(3,5)$ have been developed between $M$. truncatula and leguminous crops. Evidence for microsynteny between the M. truncatula and pea genomes was also reported in the SYM2 region of pea (8).

The broad host range of many strains of $A$. euteiches and high levels of synteny between $M$. truncatula and major leguminous crops suggests that genetic determinants of resistance to an $A$. 
euteiches strain may be conserved and localized in syntenic positions between $M$. truncatula and leguminous crops (particularly pea and alfalfa). Genetic and genomic analysis of resistance to $A$. euteiches in $M$. truncatula would then greatly facilitate syntenybased identification and functional analysis of genes involved in the resistance in leguminous crops. It would also contribute to an improved understanding of the functional basis of plant-pathogen interactions, currently under investigation in the $M$. truncatula-A. euteiches pathosystem.

This study aimed to analyze genetics of resistance to a broad host-range pea-infecting strain of $A$. euteiches in $M$. truncatula by (i) studying the inheritance of resistance in a population derived from a cross between two accessions contrasting for resistance and (ii) localizing genetic determinants associated with the resistance on the $M$. truncatula genome.

\section{MATERIALS AND METHODS}

Plant and pathogen materials. Two M. truncatula inbred lines, DZA045.5, originating from Algeria and F83005.5, originating from the French cv. Salernes, France, were used as $A$. euteiches-resistant and -susceptible parental lines, respectively (25). A population of $178 \mathrm{~F}_{5}$-derived recombinant inbred lines (RILs) produced by single-seed descent from the cross F83005.5 as female and DZA045.5 as male was used to address inheritance of resistance and mapping ( $M$. truncatula stock center, INRA Mauguio, France). A population of $200 \mathrm{~F}_{3}$ families derived from the cross F83005.5 $\times$ DZA045.5 was screened for resistance to determine genetic effect (dominant, recessive) of resistance. A population of $263 \mathrm{~F}_{2}$ plants derived from the reciprocal cross DZA045.5 as female and F83005.5 as male was evaluated to check for possible maternal effects on resistance. Two pea lines, Baccara (F. Desprez, France) and PI180693 (United States Department of Agriculture Plant Introduction Station, Pullman, WA), were used as controls in disease resistance experiments.

The RB84 strain of A. euteiches (INRA, Rennes, France), isolated from a diseased pea plant from a field in Riec-sur-Belon, Finistère, France, was used in disease screening experiments. This strain belongs to the main French pea virulence group defined by Wicker and Rouxel (43). It has a broad host range within cultivated legumes because it is pathogenic on pea, Medicago spp., bean, lentil, and vetch (24).

Disease resistance testing. Disease resistance tests were performed using a protocol adapted from Moussart et al. (26). The $\mathrm{F}_{5}$-derived RIL population, $M$. truncatula parental lines, and pea control lines were screened twice in a growth chamber $\left(25^{\circ} \mathrm{C}\right.$ for $16 \mathrm{~h}$, day; $23^{\circ} \mathrm{C}$ for $8 \mathrm{~h}$, night) for resistance to A. euteiches. The experiment was conducted using a randomized complete block design with two blocks, each block including one pot of five plants per line. Seven seeds per pot were sown in a moistened vermiculite substrate. Ten days after sowing, the number of seedlings per pot was adjusted at five. Seedlings were then inoculated by dispensing, in each pot substrate, $25 \mathrm{ml}$ of an inoculum solution adjusted to 2,000 zoospores/ml, produced according to Moussart et al. (27). After inoculation, vermiculite was saturated with water in order to favor disease development. Fourteen days after inoculation, the plants were uprooted and disease severity was scored on each individual plant using a 0 to 5 disease scoring scale adapted from Moussart et al. (25), where $0=$ no symptoms; $1=$ traces of discoloration on rootlets $(<25 \%) ; 2=$ discoloration of 25 to $50 \%$ of the roots, with some symptoms on the main root, no symptoms on hypocotyl; $3=$ discoloration of 50 to $75 \%$ of the roots, with large symptoms on the main roots, the hypocotyl may be slightly colored but stays firm; $4=$ discoloration of $>75 \%$ of the roots, discolored and soft hypocotyl; and $5=$ roots completely rotted, narrowed hypocotyl, dead plant. A root rot index (RRI) ranging from 0 to 5 was then calculated as the mean disease score on all plants in one pot.
The $\mathrm{F}_{3}$ population was evaluated in one disease test, as described for the RIL population. A mean score was calculated over a total of 10 plants assayed for each $F_{3}$ family. The $F_{2}$ population was screened in a randomized design and a 0-to-5 score was attributed to each individual plant.

DNA extraction and molecular marker amplification. Young leaves were harvested from 4-week-old plants from the $178 \mathrm{~F}_{5^{-}}$ derived RILs and the two parental lines (10 plants/line). DNA of each RIL was extracted from $\approx 1 \mathrm{~g}$ of leaf tissue according to Doyle and Doyle (7).

Amplified fragment length polymorphism (AFLP) assays were conducted as described by Vos et al. (40), using EcoRI plus MseI restriction enzymes. SSR amplifications were carried out using the procedure described on pea by Loridon et al. (20) at one annealing temperature $\left(\mathrm{Tm}=55^{\circ} \mathrm{C}\right.$ ) for all the SSRs. AFLP and SSR amplification products were electrophoresed on 5.5 and $6.5 \%$ denaturing polyacrylamide gels, respectively, and detected using a LICOR IR ${ }^{2}$ automated Sequencer (Li-Cor Inc., Lincoln, NE). AFLP image analysis was conducted using AFLP QuantarPro software (v1.04; Keygene, Wageningen, The Netherlands). SSR polymorphic bands were scored visually. Each AFLP marker was named using a code for the EcoRI/MseI primer combination as defined by the KeyGene nomenclature (available online by the USDA), followed by the length of the fragment (in base pairs). SSR markers were designed "MTIC" followed by the SSR number.

Random-amplified polymorphic DNA (RAPD) amplifications were carried out using Operon primers (Operon Technologies, Alameda, CA), according to the procedure described on pea by Laucou et al. (18). RAPD markers were named using the Operon primer name (kit letter + primer number) followed by the length of the fragment in base pairs.

Phenotypic data and genetic linkage analysis. Statistical variance analysis of phenotypic data from the two disease resistance tests on the RIL population was performed using the generalized linear model procedure (PROC GLM, SAS/STAT software; SAS Institute Inc., Cary, NC), according to the model $P i j k=\mu+L i+T j+B k / j+(L i \times T j)+e i j k$, where Pijk is the mean disease score of the $i$ th RIL located in the $k$ th block of the $j$ th test, $\mu$ is the mean of all the data, $L i$ is the RIL $i$ effect, $T j$ is the test $j$ effect, $B k / j$ is the block $k$ effect in the $j$ th test, $L i \times T j$ is the RIL $i$ $\times$ test $j$ interaction effect, and eijk is the residual. Normality of residues and homogeneity of variances were checked using Skewness, Kurtosis, and Shapiro-Wilk $(P \geq 0.05)$ statistics and Bartlett's test $(P>0.05)$, respectively. Mean-based heritability $\left(h^{2}\right)$ was calculated from analysis of variance (ANOVA) using the formula $h^{2}=\sigma_{G}^{2} /\left[\sigma_{G}^{2}+\left(\sigma_{e}^{2} / r\right)\right]$ with $\sigma_{G}^{2}$ as the genetic variance, $\sigma_{e}^{2}$ the residual variance, and $r$ the number of replicates (disease test) per line. A Pearson correlation coefficient $\left(r^{2}\right)$ was calculated between the two RIL disease tests. RIL adjusted means were estimated from ANOVA and used for linkage analysis. A $\chi^{2}$ probability value $(\alpha=0.05)$, testing the fit of the observed ratios to a $1: 1$ (RIL population) or $3: 1\left(\mathrm{~F}_{2}\right.$ and $\mathrm{F}_{3}$ populations) expected Mendelian ratio, was calculated from adjusted means (RIL population), mean scores ( $F_{3}$ population $)$, or individual plant scores $\left(F_{2}\right.$ population).

Genetic linkage analyses were performed using MAPMAKER/ EXP, version 3.0 (19), with a default $\log$ of the likelihood ratio (LOD) score threshold of 3.0 and a recombination frequency $\leq 0.4$. Linkage group and marker order were established using the "group," "order," "compare," and "try" commands, then verified using the "ripple" command. Adjustment of each marker segregation to the expected 1:1 Mendelian ratio was analyzed using a $\chi^{2}$ test $(\alpha=0.05)$. QTL analysis was performed by Composite Interval Mapping using Windows-QTL Cartographer software version 1.21 (4), set at model 6, one cofactor selected by forwardbackward regression $(P<0.10)$, and window size of 10 centimorgans (cM). 


\section{RESULTS}

Disease resistance data. Two types of symptoms were observed on inoculated plants (parental and segregating lines): (i) limited dark necrosis on the roots, especially observed on the resistant parent DZA045.5, typical of hypersensitive responses, from which the pathogen could not be reisolated and (ii) extended soft brown rotting of the roots and hypocotyl, as observed on the susceptible parent F83005.5, from which the pathogen could be easily reisolated.

ANOVA of the root rot index scored over the two tests in the RIL population $\left(R^{2}=0.89\right.$, coefficient of variation $\left.=15.8\right)$ showed highly significant effects of the genotype $(P<0.0001)$, disease test $(P<0.0001)$, and block in each test $(P<0.0001)$. The genotype $\times$ test interaction effect was not significant $(P=0.41)$, in accordance with the highly significant correlation observed between the two tests $\left(r^{2}=0.88, P<0.001\right)$. Mean-based heritability was very high $\left(h^{2}=0.92\right)$. RRI adjusted means in the RIL population were distributed following a bimodal curve (Fig. 1), with a disease severity median value of 2.46 . Therefore, two phenotypic classes were defined: a class of "resistant" lines, with adjusted mean scores ranging from 0 to 2.5 , and a class of "susceptible" lines, with adjusted mean scores $>2.5$. According to these two classes, the resistant:susceptible (R:S) ratio observed (90:87, R:S) fit a 1:1 Mendelian ratio $\left(\chi^{2}=0.05 ; P=0.82\right)$, confirming monogenic control of resistance.

The frequency distribution of the $200 \mathrm{~F}_{3}$ families for RRI followed a bimodal curve, with $154 \mathrm{~F}_{3}$ families scored as resistant (mean RRI $=0$ to 2.5 ) and 46 families as susceptible (mean RRI = 2.5 to 5) (Fig. 2). The observed ratio fit a 3:1 Mendelian ratio $\left(\chi^{2}=0.43 ; P=0.51\right)$, suggesting dominant monogenic control of resistance to A. euteiches strain RB84.

Disease scores of the $263 \mathrm{~F}_{2}$ plants from the reciprocal cross DZA045.5 $\times$ F83005.5 were also distributed according to a bimodal curve (data not shown), with 191 resistant plants (disease score $=0,1$, or 2) and 72 susceptible plants (disease score $=3,4$, or 5). The observed 3:1 Mendelian ratio $\left(\chi^{2}=0.30 ; P=0.58\right)$ suggested no maternal effect on the expression of the resistance gene.

According to guidelines established for genetic nomenclature in M. truncatula (38), the major dominant gene identified in this study was named $A E R I$, standing for A. euteiches resistance and the number " 1 " for first gene associated with this resistance phenotype, because other loci associated with the same phenotype may be expected using other $M$. truncatula sources of resistance or other A. euteiches strains.

Molecular mapping of the major resistance locus, AER1. Molecular markers putatively linked to the major resistance gene $A E R I$ were identified by bulk segregant analysis (23). Based on phenotypic data, two DNA bulks were made by pooling equal amounts of DNA from the eight most resistant RILs and the eight most susceptible RILs, respectively.

DNA samples from the two parental lines and the resistant and susceptible plant bulks were screened for polymorphisms using SSR, AFLP, and RAPD markers. A set of 221 oligonucleotide primer pairs designed to amplify SSRs identified within EST se-

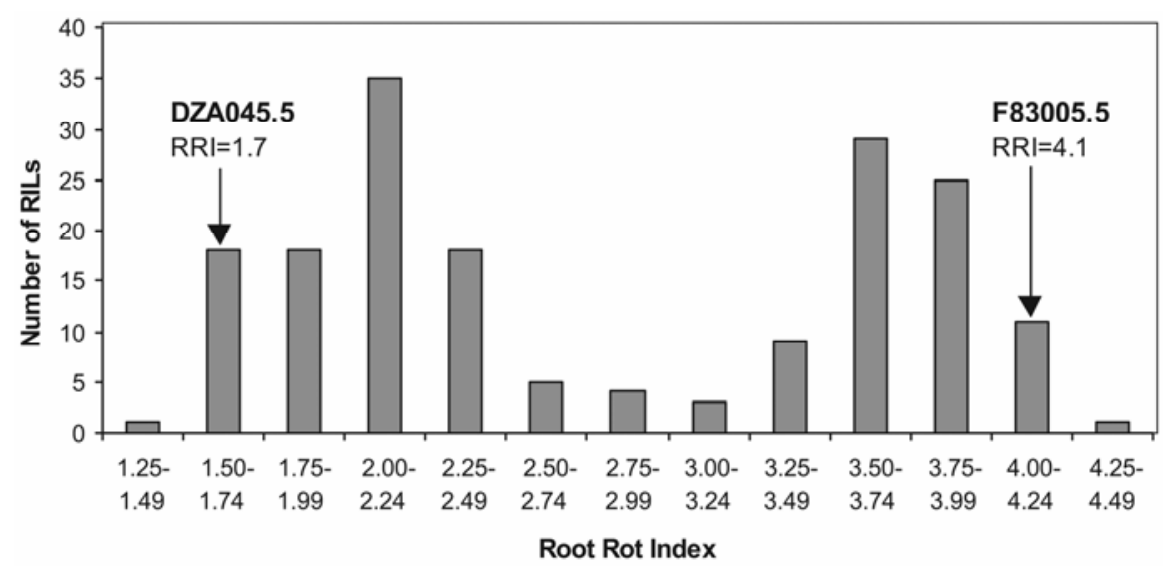

Fig. 1. Frequency distribution of resistance to Aphanomyces euteiches strain RB84 in F83005.5 × DZA045.5 Medicago truncatula recombinant inbred lines (RILs) (adjusted mean root rot index [RRI] over two disease tests). Total number of RILs assessed was 177. The mean and standard deviation of the RIL population for RRI was $2.8 \pm 0.9$. The RRI scorings in the RIL population ranged from 1.4 to 4.4 .

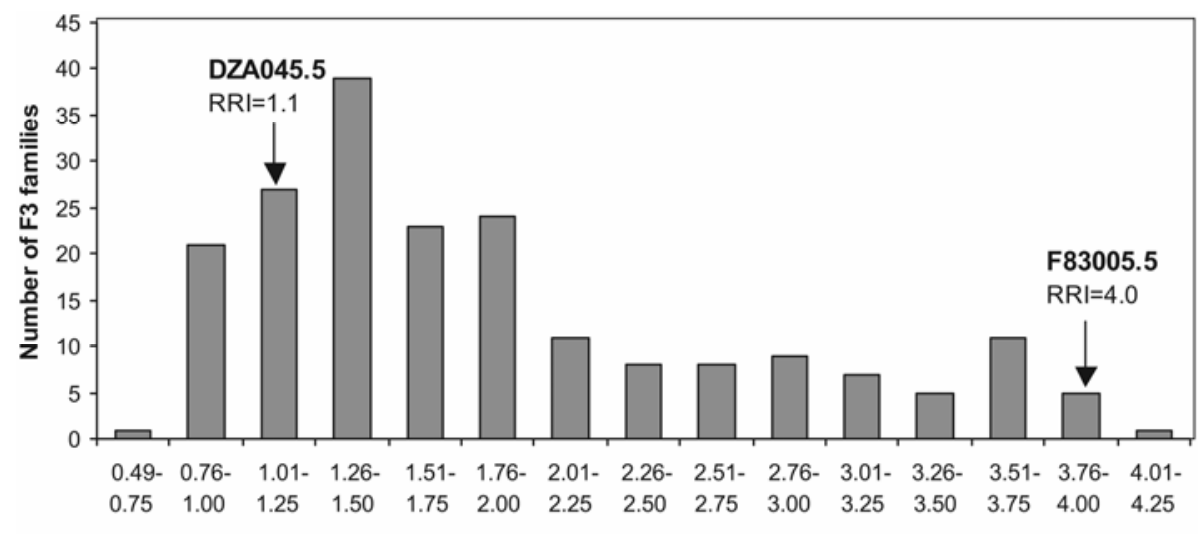

Root Rot Index

Fig. 2. Frequency distribution of resistance to Aphanomyces euteiches strain RB84 in F83005.5 $\times$ DZA045.5 Medicago truncatula $\mathrm{F}_{3}$ families (mean root rot index [RRI] on 10 plants per family). The total number of $F_{3}$ families assessed was 200 . The mean and standard deviation of the $F_{3}$ population for RRI was $1.9 \pm 0.8$. The RRI scorings in the $\mathrm{F}_{3}$ population ranged from 0.75 to 4.1 . 
quences in $M$. truncatula (11) were used to test for polymorphisms between resistant and susceptible parents. GenBank EST identification number (ID), SSR repetitive motifs, and primer sequences are described as electronic supplementary material by Guttierez et al. (9). A subset of 73 EST-SSRs that were polymorphic between the two parental lines and mapped to the Jemalong. 6 $\times$ DZA315.16 $\left(\mathrm{F}_{6}\right)$ genetic map (Huguet et al., unpublished data) were subsequently used to check for polymorphisms between the two bulks. AFLP and RAPD screening for polymorphisms between the resistant and susceptible parents and the two bulks was performed using (i) 18 Operon RAPD primers, previously used by Thoquet et al. (33) to generate the Jemalong. $6 \times$ DZA315-16 $\left(\mathrm{F}_{2}\right)$ genetic map of $M$. truncatula, and (ii) 64 selective AFLP primer pairs, from the four EcoRI-AN(N) primers used in Thoquet et al. (33) and $16 \mathrm{Mse}$ I-CNN primers (Table 1).

Markers displaying polymorphisms between susceptible and resistant bulks were subsequently screened on the 16 individual RILs of the two bulks. Fifteen AFLP markers amplified from 10 AFLP primer combinations, plus two RAPD and two SSR markers, co-segregated with the resistance gene, with 0 or 1 recombinant genotypes detected among the 16 samples of the two bulks. An additional SSR marker (MTIC051), for which one recombinant out of 14 RILs of the two bulks was found, was kept for further analysis as an anchor marker to the Jemalong. $6 \times$ DZA315.16 genetic map $(3,12)$ and to the integrated genetic map of M. truncatula. Genetic linkage between 17 markers (12 AFLP, 2 RAPD, and 3 SSR) and the AERl locus was then confirmed on the 178 RILs. Of the 14 AFLP and RAPD markers cosegregating with $A E R 1,5$ were in coupling phase with the DZA045.5 resistance allele at AER1. All of the 17 markers segregated in the RIL population according to a $1: 1$ Mendelian ratio $(P \leq 0.01)$. A linkage group comprising the 17 markers and covering $53 \mathrm{cM}$ was then constructed in the region of AERl (Fig. 3). The linkage group was assigned to LG3 of M. truncatula, based on the three SSR markers (MTIC169, MTIC124, and MTIC051), which mapped to the Jemalong. $6 \times$ DZA315.16 genetic map in the same order as on the linkage group established in this study.

Genomic localization of $A E R I$ on the constructed linkage group was identified using qualitative disease scores (resistant and susceptible) and quantitative adjusted mean RRI scores obtained in the RIL population. Using qualitative scores, the AERI locus was localized on LG3 between the two AFLP markers E12M49.384 and E12M47.541 at an estimated genetic distance of $1.2 \mathrm{cM}$ from the closest marker E12M47.541 (Fig. 3). The two

TABLE 1. Amplified fragment length polymorphism primer combinations employed to generate fingerprints ${ }^{\mathrm{a}}$

\begin{tabular}{lllll}
\hline & \multicolumn{4}{c}{ Primers } \\
\cline { 2 - 5 } Primers & \multicolumn{1}{c}{ E-AC } & \multicolumn{1}{c}{ E-AG } & \multicolumn{1}{c}{ E-AT } & \multicolumn{1}{c}{ E-AGA } \\
\hline M-CAA & E12M47 & E13M47 (PB) & E14M47 & E39M47 \\
M-CAC & E12M48 (PI) & E13M48 (PA) & E14M48 (PD) & E39M48 \\
M-CAG & E12M49 & E13M49 & E14M49 (PE) & E39M49 \\
M-CAT & E12M50 (PK) & E13M50 (PC) & E14M50 & E39M50 \\
M-CCA & E12M51 & E13M51 & E14M51 & E39M51 (PG) \\
M-CCC & E12M52 & E13M52 & E14M52 & E39M52 \\
M-CCG & E12M53 & E13M53 & E14M53 & E39M53 \\
M-CCT & E12M54 & E13M54 & E14M54 & E39M54 \\
M-CGA & E12M55 & E13M55 & E14M55 & E39M55 \\
M-CGC & E12M56 & E13M56 & E14M56 & E39M56 \\
M-CGG & E12M57 & E13M57 (PM) & E14M57 & E39M57 \\
M-CGT & E12M58 & E13M58 & E14M58 & E39M58 (PF) \\
M-CTA & E12M59 & E13M59 (PL) & E14M59 & E39M59 \\
M-CTC & E12M60 & E13M60 & E14M60 & E39M60 \\
M-CTG & E12M61 (PH) & E13M61 & E14M61 & E39M61 \\
M-CTT & E12M62 (PJ) & E13M62 & E14M62 & E39M62 \\
\hline
\end{tabular}

${ }^{\text {a }}$ E indicates EcoRI primer 5'-GAC TGC GTA CCA ATT C+ANN-3' and M indicates MseI primer 5'-GAT GAG TCC TGA GTA A+CNN-3'. In parentheses, code names of EcoRI/MseI primer combinations used in Thoquet et al. (33). flanking AFLP markers were in repulsion phase with the DZA045.5 resistance allele at AER1. The closest SSR marker to $A E R 1$ was MTIC169, which was positioned $6 \mathrm{cM}$ from the resistance locus. Using quantitative scores, AERl was detected between the AFLP markers E39M61.109 and E13M50.412 spanning an interval of $22.6 \mathrm{cM}$ (Fig. 4), with a highest probable position at $0.8 \mathrm{cM}$ from the marker E12M47.541 (LOD = 73.7). At the LOD peak, AER1 explained $88 \%$ of the total phenotypic variation observed and its additive genetic effect (i.e., effect of substituting DZA045.5 alleles for F83005.5 alleles) was estimated to be 0.82 .

\section{DISCUSSION}

$A E R 1$, a major gene controlling resistance to $A$. euteiches in $M$. truncatula, is identified in a resistance-gene-rich region of chromosome 3 . In this article, we report the identification and mapping of $A E R 1$, a major dominant resistance gene in $M$. truncatula DZA045.5 to RB84, a broad host-range pea-infecting strain of A. euteiches. In the model legume $M$. truncatula, few genomic regions have been associated with disease resistance phenotypes, although screening studies for a range of different pathogens have been reported. Major trait loci or QTL have been recently identified in $M$. truncatula for resistance to Colletotrichum trifolii $(1,44)$, Erysiphe pisi (2), Phoma medicaginis (13), Ralstonia solanacearum (35), and aphids $(14,15)$.

The AER1 major resistance locus was localized at a telomeric end of LG3 on the $M$. truncatula genetic map, based on three EST-SSR markers mapped on the reference genetic map Jemalong. $6 \times$ DZA315.16 (3). In the same region of chromosome 3 , a supercluster of nucleotide binding site leucine-rich repeat (NBS-LRR) genes was identified based on the Mt1.0 assembly genome, encoding $\approx 40 \%$ of all coiled-coil NBS-LRRs (2). Re-

\section{LG3}

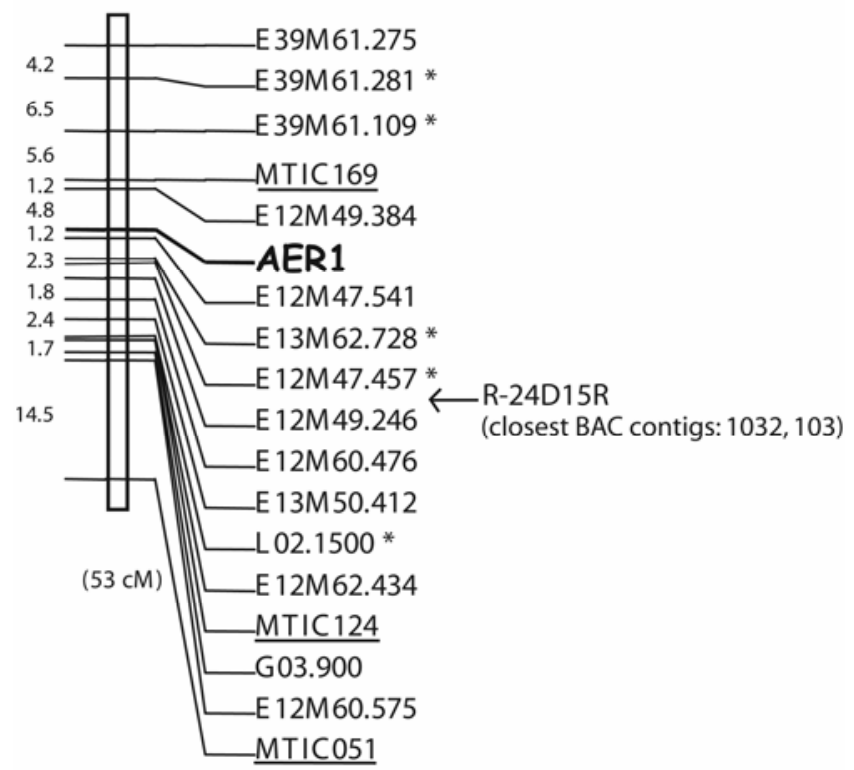

Fig. 3. Genetic linkage between $A E R 1$, the major locus conferring resistance to Aphanomyces euteiches RB84, and cosegregating markers identified by bulk segregant analysis. Expressed-sequence-tag simple-sequence-repeat markers anchored to LG3 of the Jemalong.6 $\times$ DZA315.16 genetic map are underlined. Random amplified fragment DNA (RAPD) markers are L02.1500 and G03.900. Amplified fragment length polymorphism and RAPD markers in coupling phase with the DZA045.5 resistance allele at AERI are indicated by an asterisk (*). The genetic position of the additional marker R-24D15R, anchored to the Medicago truncatula physical map (closest BAC contig numbers: 1,032 and 103), is indicated by an arrow. Genetic distances between markers are indicated on the left of the linkage group, in centimorgans (cM) Kosambi. The total size of the linkage group is indicated at the bottom in centimorgans. 
sistance gene analog (RGA) markers were developed especially for NBS-LRR genes on chromosome 3 (46). In our study, we could additionally map one of these RGA markers, namely R24D15R, between markers E12M47.457 and E12M49.246 of the linkage group built around $A E R 1$, at a genetic distance of $8.6 \mathrm{cM}$ from $A E R 1$ (Fig. 3). The RGA cluster identified on LG3 contained sequences from different phylogenetic groups of RGAs that were cophyletic with RGAs present in at least one other cluster identified on the $M$. truncatula genome (46). Such heterogeneous RGA clusters suggest occurrence of genomic evolution events in the region, such as sequence divergence due to diversifying selection after duplication, selective gene loss, or ectopic recombination among physically distinct clusters.

Interestingly, other genes or QTL associated with resistance phenotypes were reported to map to the same region as AERI on chromosome 3. Klingler et al. (14) mapped the $A K R$ locus, conferring resistance to bluegreen aphid (Acyrthosiphon kondoi Shinji), to the RGA cluster region of LG3 but at a different genomic position as AERl. Klingler et al. (15) mapped the TTR locus, for resistance to spotted alfalfa aphid (Therioaphis trifolii), to a separate but linked position to $A K R$ on chromosome 3. For resistance to the soilborne bacterium $R$. solanacearum, Vailleau et al. (35) identified a minor QTL on LG3, accounting for $13.1 \%$ of the phenotypic variation, located in the same region as $A E R 1$, based on flanking markers mapped on the integrated genetic map (28).

Thus, the resistance locus $A E R l$ is located in a resistance gene rich region of the $M$. truncatula chromosome 3, in which RGAs and genes associated with disease resistance phenotypes have been identified. Such clusters of resistance genes have frequently been observed in other plant species.

Toward comparative genomics of resistance to A. euteiches in legumes. Work is in progress for fine mapping and identifying the physical genomic region associated with the AERl locus, using SSR genetic markers anchored to the physical map (28). AERl genomic localization will be compared with genetic factors involved in resistance of the genomic reference genotype A17 (6), which was reported to be intermediate $(25,37)$. The isolation of $A E R I$ will be greatly facilitated by numerous genomic tools now available in M. truncatula, including the Mt2.0 genome assembly,

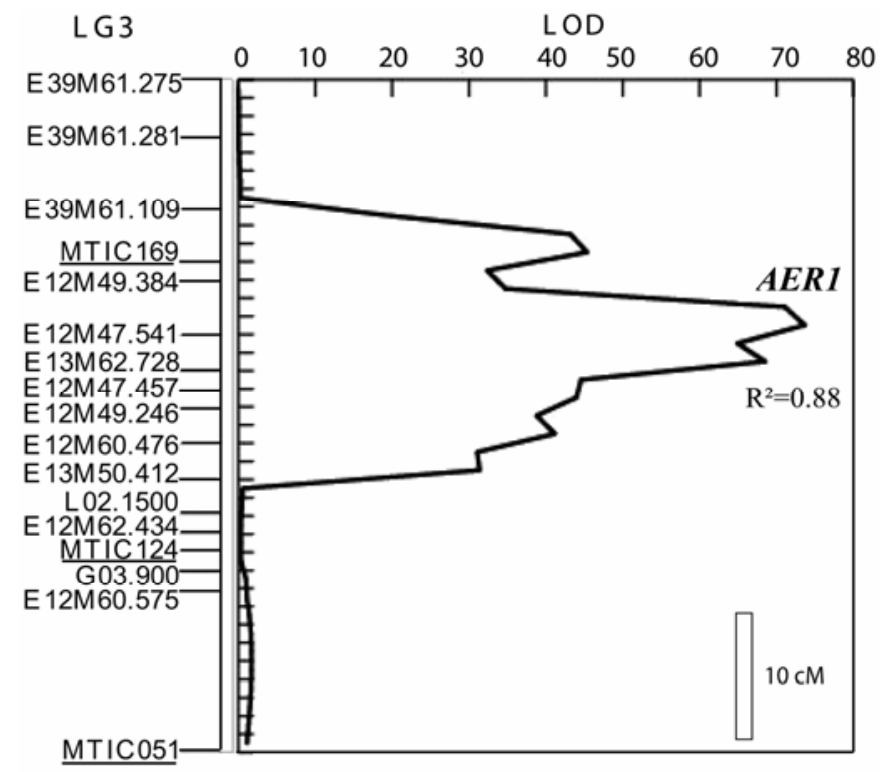

Fig. 4. Log of the likelihood ratio (LOD) curve in the AER1 region for resistance to Aphanomyces euteiches RB84, obtained from quantitative disease scores in the Medicago truncatula F83005.5 $\times$ DZA045.5 recombinant inbred lines population (QTL-Cartographer V.1.21/Windows). Expressedsequence-tag simple-sequence-repeat markers anchored to LG3 of the Jemalong. $6 \times$ DZA315.16 genetic map are underlined. $R^{2}=$ percentage of phenotypic variation explained by $A E R 1$ at the LOD peak. mutant collections, oligonucleotide microarrays, and Agrobacterium spp.-mediated transformation. Sequence identification of $A E R 1$ will provide new prospects for comparative genomic studies of the resistance gene within legume species infected by Aphanomyces euteiches, including alfalfa and pea. Such studies will aim at (i) identifying $A E R 1$-orthologous genes in cultivated legumes, (ii) analyzing their synteny to $A E R I$ and their colocalization with Aphanomyces resistance QTL or genes identified in leguminous crops, and (iii) validating their involvement in the resistance of cultivated legumes, especially using ecotilling and tilling strategies. This comparative approach would be particularly useful for identifying resistance genes in tetraploid alfalfa, in which no genetic factors associated with resistance to A. euteiches have been mapped (36). Populations of alfalfa-infecting strains of A. euteiches in the United States have been structured in two pathotypes, namely race 1 and race 2 , based on reactions of three alfalfa populations (Saranac, WAPH-1, and WAPH-5) under standardized testing conditions $(21,22)$. Resistance of alfalfa to the two races of $A$. euteiches is expected to be controlled by different genes because many alfalfa populations are resistant to race 1 but susceptible to race 2 (36). Recently, reactions of the three reference alfalfa populations to infection by RB84, using the same screening conditions as described in this study, were found to be typical of responses observed with race 1 strains according the definition of races used in Malvick et al. (22) (average RRI $>3$ on Saranac, average RRI $<3$ on WAPH-1 and WAPH-5) (Onfroy, personal communication).

Comparative genetics and genomics of resistance to A. euteiches could also be more extensively investigated within legumes, when additional information is available about diversity of genetic factors involved in the resistance in $M$. truncatula. Work is in progress to analyze the spectrum of action of AERl toward $A$. euteiches pathotypes and to identify putative new genes associated with resistance to other A. euteiches pathotypes in DZA045.5 and in other sources of resistance in M. truncatula. Analysis of synteny between Aphanomyces resistance genetic factors in $M$. truncatula and other legumes will yield new information regarding gene conservation between species and the possible extent of information transfer from model to crop legumes. An analysis currently in progress between $M$. truncatula and pea has not detected synteny between AERI and Aphanomyces resistance QTL identified in pea $(30,31)$, although other disease resistance QTL or genes have been identified in the AERl syntenic region on LGIII in pea $(5,32,41)$. Despite rapid evolution of resistance genes, synteny of resistance genes has already been reported in plants, especially in the family Solanaceae (10), making comparative genomics a promising approach for improving disease resistance in cultivated crops.

\section{ACKNOWLEDGMENTS}

This work was funded by Institut National de la Recherche Agronomique (INRA), France and the FP6 EU Grain Legume Integrated Project (FOOD-CT-2004-506223) (GLIP). We thank A. Moussart and B. Tivoli for providing the A. euteiches strain used in this study and for their critical review of the manuscript. We thank the genotyping platform of Ouest-Génopôle, Rennes, France, for technical assistance.

\section{LITERATURE CITED}

1. Ameline-Torregrossa, C., Cazaux, M., Danesh, D., Chardon, F., Cannon, S. B., Esquerré-Tugayé, M-T., Dumas, B., Young, N. D., Samac, D. A., Huguet, T., and Jacquet, C. 2008. Genetic dissection of resistance to anthracnose and powdery mildew in Medicago truncatula. Mol. PlantMicrobe Interact. 21:61-69.

2. Ameline-Torregrossa, C., Wang, B.-B., O’Bleness, M. S., Deshpande, S., Zhu, H., Roe, B., Young, N. D., and Cannon, S. B. 2008. Identification and characterization of Nucleotide Binding Site- Leucine Rich Repeat genes in the model plant Medicago truncatula. Plant Physiol. 146:5-21.

3. Aubert, G., Morin, J., Jacquin, F., Loridon, K., Quillet, M.-C., Petit, A., 
Rameau, C., Lejeune-Hénaut, I., Huguet, T., and Burstin, J. 2006. Functional mapping in pea, as an aid to the candidate gene selection and for investigating synteny with the model legume Medicago truncatula. Theor. Appl. Genet. 112:1024-1041.

4. Basten, C. J., Weir, B. S., and Zeng, Z. B. 2001. Windows QTL Cartographer 1.21. Department of Statistics, North Carolina State University, Raleigh.

5. Choi, H. K., Mun, J. H., Kim, D. J., Zhu H., Baek, J. M., Mudge, J., Roe, B., Ellis, N., Doyle, J., Kiss, G. B., Young, N. D., and Cook, D. R. 2004. Estimating genome conservation between crop and model legume species. Proc. Natl. Acad. Sci. USA 101:15289-15294.

6. Djebali, N., Jauneaux, A., Ameline-Torregrossa, C., Moumene, A., Bottin, A., Esquerre-Tugayé, M.-T., Dumas, B., Aouani, E., Huguet, T., and Jacquet, C. 2007. Cytological analyses and QTL cloning to identify Medicago truncatula candidate genes involved in resistance to Aphanomyces euteiches. Page 54 in: Book of Abstract Model Legume Congress, INP-ENSAT-ICARDA, eds. Tunis, Tunisia.

7. Doyle, J. J., and Doyle, J. L. 1990. Isolation of plant DNA from fresh tissue. Focus 12:13-15.

8. Gualtieri, G., Kulikova, O., Limpens, E., Kim, D. J., Cook, D. R., Bisseling, T., and Geurts, R. 2002. Microsynteny between pea and Medicago truncatula in the SYM2 region. Plant. Mol. Biol. 50:225-235.

9. Guttierez, M. V., Vaz Patto, M. C., Huguet, T., Cubero, J. I., Moreno, M. T., and Torres, A. M. 2005. Cross-species amplification of Medicago truncatula microsatellites across three major pulse crops. Theor. Appl. Genet. 110:1210-1217.

10. Huang, S., Van der Vossen, E. A., Kuang, H., Vleeshouwers, V. G., Zhang, N., Borm, T. J., Van Eck, H. J., Baker, B., Jacobsen, E., and Visser, R. G. 2005. Comparative genomics enabled the isolation of the $R 3 a$ late blight resistance gene in potato. Plant J. 42:251-261.

11. Julier, B., Flajoulot, S., Barre, P., Cardinet, G., Santoni, S., Huguet, T., and Huyghe, C. 2003. Construction of two genetic linkage maps in cultivated tetraploid alfalfa (Medicago sativa) using microsatellite and AFLP markers. BMC Plant Biol. 3:9.

12. Julier, B., Huguet, T., Chardon, F., Ayadi, R., Pierre, J.-B., Prosperi, J.-M., Barre, P., and Huyghe, C. 2007. Identification of quantitative trait loci influencing aerial morphogenesis in the model legume Medicago truncatula. Theor. Appl. Genet. 114:1391-1406.

13. Kamphuis, L. G., Lichtenzveig, J., Oliver, R. P., and Ellwood, S.R. 2008. Two alternative recessive quantitative trait loci influence resistance to spring black stem and leaf spot in Medicago truncatula. BMC Plant Biol. 8:30.

14. Klingler, J. P., Creasy, R., Gao, L., Nair, R. M., Calix, A. S., Jacob, H. S., Edwards, O. R., and Singh, K. B. 2005. Aphid resistance in Medicago truncatula involves antixenosis and phloem-specific, inducible antibiosis and maps to a single locus flanked by NBS-LRR resistance gene analogs. Plant Physiol. 137:1445-1455.

15. Klingler, J. P., Edwards, O. R., and Singh, K. B. 2007. Independent action and contrasting phenotypes of resistance genes against spotted alfalfa aphid and bluegreen aphid in Medicago truncatula. New Phytol. 173:630-640

16. Kraft, J. M., and Coffman, V. A. 2000. Registration of 96-2052, 96-2058, 96-2068, 96-2198 and 96-2222 pea germplasms. Crop Sci. 40:301-302.

17. Kraft, J. M., and Pfleger, F. L. eds 2001. Compendium of Pea Diseases and Pests, 2nd ed. The American Phytopathological Society, St. Paul, MN.

18. Laucou, V., Haurogné, K., Ellis, N., and Rameau, C. 1998. Genetic mapping in pea. 1. RAPD-based genetic linkage map of Pisum sativum. Theor. Appl. Genet. 97:905-915

19. Lincoln, S., Daly, M., and Lander, E. S. 1992. Constructing genetic maps with Mapmaker/Exp3.0. Whitehead Institute Technical Report, 3rd ed. Cambridge, MA.

20. Loridon, K., McPhee, K. E., Morin, J., Dubreuil, P., Pilet-Nayel, M.-L., Aubert, G., Rameau, C., Baranger, A., Coyne, C. J., Lejeune-Hènaut, I., and Burstin, J. 2005. Microsatellite marker polymorphism and mapping in pea (Pisum sativum L.). Theor. Appl. Genet. 111:1022-1031.

21. Malvick, D. K., and Grau, C. R. 2001. Characteristics and frequency of Aphanomyces euteiches races 1 and 2 associated with alfalfa in the Midwestern United States. Plant Dis. 85:740-744.

22. Malvick, D. K., Grünwald, N. J., and Dyer, A. T. 2008. Population structure, races, and host range of Aphanomyces euteiches from alfalfa production fields in the central USA. Eur. J. Plant Pathol. DOI: 10.1007/s10658-008-9354-6.

23. Michelmore, R. W., Paran, I., and Kesseli, R. V. 1991. Identification of markers linked to disease-resistance genes by bulked segregant analysis: a rapid method to detect markers in specific genome region by using segregating population. Proc. Natl. Acad. Sci. USA 88:9828-9832.

24. Moussart, A., Even, M.-N., and Tivoli, B. 2008. Reaction of genotypes from several species of grain and forage legumes to infection with a French pea isolate of the oomycete Aphanomyces euteiches. Eur. J. Plant Pathol. 122:321-333.

25. Moussart, A., Onfroy, C., Lesné, A., Esquibet, M., Grenier, E., and Tivoli, B. 2007. Host status and reaction of Medicago truncatula accessions to infection by three major pathogens of pea (Pisum sativum) and alfalfa (Medicago sativa). Eur. J. Plant Pathol. 117:57-69.

26. Moussart, A., Tivoli, B., Samac, D. A., and D'Souza, N. 2006. Medicago truncatula resistance to Oomycetes. In: The Medicago truncatula handbook, http://www.noble.org/MedicagoHandbook/.

27. Moussart, A., Wicker E., Duparque M., and Rouxel F. 2001. Development of an efficient screening test for pea resistance to Aphanomyces euteiches. Pages 272-273 in: Proc. 4th Eur. Conf. Grain Legumes, Cracow, Poland. AEP, ed., Paris.

28. Mun, J. H., Kim, D. J., Choi, H. K., Gish, J., Debellé, F., Mudge, J., Denny, R., Endré, G., Saurat, O., Dudez, A. M., Kiss, G. B., Roe, B., Young, N. D., and Cook, D. R. 2006. Distribution of microsatellites in the genome of Medicago truncatula: a resource of genetic markers that integrate genetic and physical maps. Genetics 172:2541-2555.

29. Munkvold, G. P., Carlton, W. M., Brummer, E. C., Meyer, J. R., Undersander, D. J., and Grau, C. R. 2001. Virulence of Aphanomyces euteiches isolates from Iowa and Wisconsin and benefits of resistance to A. euteiches in alfalfa cultivars. Plant Dis. 85:328-333.

30. Pilet-Nayel, M.-L., Muehlbauer, F. J., McGee, R. J., Kraft, J. M., Baranger, A., and Coyne, C. J. 2002. Quantitative trait loci for partial resistance to Aphanomyces root rot in pea. Theor. Appl. Genet. 106: 28-39.

31. Pilet-Nayel, M.-L., Muehlbauer, F. J., McGee, R. J., Kraft, J. M., Baranger, A., and Coyne, C. J. 2005. Consistent quantitative trait loci in pea for partial resistance to Aphanomyces euteiches isolates from the United States and France. Phytopathology 95:1287-1293.

32. Prioul-Gervais, S., Deniot, G., Receveur, E.-M., Frankewitz, A., Fourmann, M., Rameau, C., Pilet-Nayel, M.-L., and Baranger, A. 2007. Candidate genes for quantitative resistance to Mycosphaerella pinodes in pea (Pisum sativum L.). Theor. Appl. Genet. 114:971-984.

33. Thoquet, P., Ghérardi, M., Journet, E.-P., Kereszt, A., Ané, J.-M., Prosperi, J.-M., and Huguet, T. 2002. The molecular genetic linkage map of the model legume Medicago truncatula: An essential tool for comparative legume genomics and the isolation of agronomically important genes. BMC Plant Biol. 2:1.

34. Tivoli, B., Baranger, A., Sivasithamparam, K., and Barbetti, M. J. 2006. Annual Medicago: from a model crop challenged by a spectrum of necrotrophic pathogens to a model plant to explore the nature of disease resistance. Ann. Bot. 98:1117-1128.

35. Vailleau, F., Sartorel, E., Jardinaud, M. F., Chardon, F., Genin, S., Huguet, T., Gentzbittel, L., and Petitprez, M. 2007. Characterization of the interaction between the bacterial wilt pathogen Ralstonia solanacearum and the model legume plant Medicago truncatula. Mol. Plant-Microbe. Interact. 20:159-167.

36. Vandemark, G. J., Bridget, M. B., and Hughes, T. J. 2004. Heritability of resistance to Aphanomyces euteiches races 1 and 2 in alfalfa. Euphytica $136: 45-50$

37. Vandemark, G. J., and Grünwald, N. J. 2004. Reaction of Medicago truncatula to Aphanomyces euteiches race 2. Arch. Phytopathol. Plant Prot. 37:59-67.

38. VandenBosch, K. A., and Frugoli, J. 2001. Guidelines for genetic nomenclature and community governance for the model legume Medicago truncatula. Mol. Plant-Microbe Interact. 14:1364-1367.

39. Vincelli, P., Henning, J., Hendrick, T., Brown, J., Osborne, L. J., Prewitt, B., Schields, V., Sorrell, D., Strohmeier, K. D., Tackett, R., and Wyles, J. W. 2000. Improved seedling health., yield., and stand persistence with alfalfa resistant to Aphanomyces root rot. Agron. J. 92:1071-1076.

40. Vos, P., Hogers, R., Bleeker, M., Reijans, M., Van de Lee, T., Hornes, M., Frijters, A., Pot, J., Peleman, J., Kuiper, M., and Zabeau, M. 1995. AFLP: A new technique for DNA fingerprinting. Nucleic Acids Res. 23:4407-4414.

41. Weeden, N. F., Ellis, T. H. N., Timmerman-Vaughan, G. M., Swiecicki, W. K., Rozov, S. M., and Berdnikov, V. A. 1998. A consensus linkage map for Pisum sativum. Pisum Genet. 30:1-4.

42. Wicker, E., Hullé, M., and Rouxel, F. 2001. Pathogenic characteristics of isolates of Aphanomyces euteiches from pea in France. Plant Pathol. 50:433-442.

43. Wicker, E., and Rouxel, F. 2001. Specific behaviour of French Aphanomyces euteiches Drechs. populations for virulence and aggressiveness on pea, related to isolates from Europe, America and New-Zealand. Eur. J. Plant Pathol. 107:919-929.

44. Yang, S., Gao, M., Deshpande, S., Lin, S., Roe, B. A., and Zhu, H. 2007. Genetic and physical localization of and anthracnose resistance gene in Medicago truncatula. Theor. Appl. Genet. 116:45-52.

45. Young, N. D., Cannon, S. B., Sato, S., Kim, D., Cook, D. R., Town, C. D., Roe, B. A., and Tabata, S. 2005. Sequencing the gene spaces of Medicago truncatula and Lotus japonicus. Plant Physiol. 137:1174-1181.

46. Zhu, H., Cannon, S. B., Young, N. D., and Cook, D. R. 2002. Phylogeny and genomic organization of the TIR and non-TIR NBS-LRR resistance gene family in Medicago truncatula. Mol. Plant-Microbe Interact. 15:529-539. 